\title{
El Áncora Editores (Bogotá, 1980): UN ACERCAMIENTO A LA EDITORIAL Y SU CATÁlOGo*
}

\author{
El Áncora Editores (Bogotá, i 980): An \\ Approach to the Publishing House and \\ its Catalog
}

Almary Cristina Gutiérrez Díaz ${ }^{1}$

* Artículo de investigación derivado del proyecto "La edición del cuento colombiano en el siglo $\mathrm{xx}$, Poéticas y soportes", desarrollado en el marco del grupo de investigación Colombia: tradiciones de la palabra (Universidad de Antioquia), con el apoyo del Fondo Nacional de Financiamiento para la Ciencia, la Tecnología y la Innovación "Francisco José de Caldas" (colciencias). Asimismo se inscribe en la Estrategia de Sostenibilidad para grupos de investigación Universidad de Antioquia, UdeA 2018-2019.

Cómo citar este artículo: Gutiérrez Díaz, A. C. (2020). El Áncora Editores (Bogotá, 1980): un acercamiento a la editorial y su catálogo. Estudios de Literatura Colombiana 46, pp. 215230. DOI: https://doi.org/10.17533/udea.elc. n46a11

${ }^{1}$ https://orcid.org/0000-0003-0205-0725 almary.gutierrez@udea.edu.co Universidad de Antioquia, Colombia

Editores: Andrés Vergara Aguirre, Christian Benavides Martínes, Vanessa Zuleta Quintero

Recibido: 15.08 .2019

Aprobado: 21.10.2019

Publicado: 27.12.2019

Copyright: (2020 Estudios de Literatura Colombiana. Este es un artículo de acceso abierto distribuido bajo los términos de la Licencia Creative Commons AtribuciónNo comercial - Compartir igual 4.0 Internacional 


\section{Introducción}

Durante el siglo xix las publicaciones periódicas fueron el principal medio de difusión de las ideas surgidas dentro del campo intelectual nacional; sin embargo, con el florecimiento de las editoriales, a partir del siglo xx tomó fuerza el formato libro como una nueva ventana a través de la cual fue posible difundir el conocimiento. Las editoriales forman parte de un sistema de instancias que componen el campo en el que la literatura se institucionaliza; es por ello que en los últimos años los estudios alrededor de la cultura impresa en Colombia han tomado gran relevancia para comprender las dinámicas de producción y circulación de la literatura colombiana, en los que la historia del libro y de la edición es una pieza clave para desarrollar este tipo de trabajos.

A finales del siglo pasado, Colombia tuvo un crecimiento en la producción nacional de libros gracias a la disminución de los niveles de analfabetismo, a la creación del Centro Regional para el Fomento del Libro en América Latina y el Caribe (CERLALC) en 1971 con sede en Bogotá, y a la difícil situación política y económica que atravesaron países con mayor trayectoria editorial como España, México y Argentina durante la década de 1970 (franquismo, crisis económica y dictadura militar, respectivamente). Por ello, no es casualidad que a partir de ese momento se diera "un auge de la industria editorial colombiana representado en aumento en número de títulos publicados, exportaciones, número de empresas editoriales fundadas y mejora en el grado de tecnificación y equipamiento de los talleres gráficos" (Marín Colorado, 2018, p. 407).

En este ambiente de esplendor de la industria editorial nacional nació el sello de El Áncora Editores, objeto del presente estudio. Conocer sobre su historia, su línea editorial, su catálogo de libros publicados, y la experiencia de sus fundadores y editores se constituye en un trabajo pertinente para la comprensión del mercado editorial colombiano. En las siguientes páginas se propone presentar a los lectores una parte de la vida de esta empresa bogotana, como complemento al estudio del género cuento en esta misma editorial, el cual forma parte del libro La edición de cuento en Colombia en el siglo xx: apuestas editoriales y legitimación, actualmente en proceso de evaluación. 


\section{Sobre la vida de El Áncora}

ElÁncora Editores fue fundada en Bogotá en el año 1980 por la pareja conformada por Felipe Escobar y Patricia Hoher. La empresa surgió en un momento de efervescencia social en Colombia y Latinoamérica, en el que, de acuerdo con Ribadero (2016), las ideas izquierdistas originadas veinte años antes con la Revolución cubana y el movimiento de Mayo del 68 en Francia seguían vigentes en el terreno intelectual, manteniéndose gracias a la existencia de libros críticos sobre periodismo y política, que de una forma u otra buscaban reivindicar ese pasado revolucionario y afianzar el sentido nacionalista (p. 308). Patricia Hoher era una bogotana de ascendencia suiza que había trabajado en el área de ventas de la empresa Carlos Valencia Editores (Bogotá, 1975-1991) y también en Colcultura. Por su parte, Felipe Escobar había estudiado Derecho y Filosofía y Letras, y sus inquietudes editoriales nacieron durante su vida universitaria a través de trabajos en revistas académicas.

La puesta en marcha de El Áncora fue un intento por independizarse e incursionar en el mercado editorial colombiano a partir de la experiencia que ambos tenían en el área, y atender a esa pasión que compartían por los libros. Su deseo era fundar "una editorial que diera una visión alternativa, crítica, de lo que estaba pasando en el país” (Escobar, 2018, s.p.), hacer libros que llevaran las discusiones nacionales a un nivel superior, bien fuera en el tema social, político o literario, pues consideraban que "los medios de comunicación de ese momento daban información muy sesgada"; así lo expresó Felipe Escobar en conversaciones con la autora en 2018. ${ }^{1}$

La relación de negocio nació a la par de la relación sentimental de sus fundadores, un matrimonio que siempre estuvo al frente de la editorial, trabajando juntos hasta la muerte de Patricia Hoher en el año 2017. La pareja tenía "una vida como muy dispersa, y el ancla es como un símbolo de estabilidad, de que por fin asentaste cabeza [...] fue por eso que decidimos ponerle ese nombre a la editorial", así lo dijo Felipe Escobar (2018) en la conversación antes citada, refiriéndose al nombre y logo que representa a la empresa (figura 1). Desde el inicio, las actividades de la editorial fueron distribuidas entre Hoher y Escobar: 
Patricia era la gerente general de El Áncora, la que manejaba todo lo que tiene que ver con las ventas, con la administración de la editorial. $Y$ yo me encargaba de la producción de los libros: de escoger los autores, de entenderme con los autores, hacer que los libros se hicieran y se publicaran (Escobar, 2018).

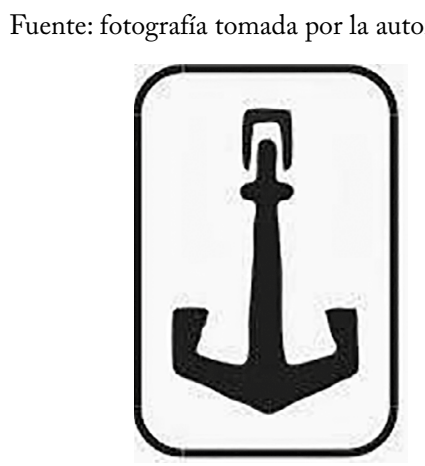

Figura 1. Logo de E1 Áncora Editores.

Durante la década de 1980, los libros de El Áncora aparecieron en varias oportunidades dentro de las listas de los más vendidos del suplemento Lecturas Dominicales del periódico bogotano El Tiempo; por ejemplo, en los números de diciembre de 1983, enero y noviembre de 1984, diciembre de 1987, entre otros. Durante esos mismos años, en el suplemento Magazine Dominical de El Espectador de Bogotá se publicaron reseñas y anuncios de las obras de la editorial, en los cuales afirmaban que se encontraban "de venta en todas las librerías del país" (Magazine Dominical, 1985, s.p.). Este tipo de publicidad aparecía periódicamente en formato extenso de página completa y algunas veces con imágenes a color de los libros (figuras 2 y 3 ). También, en una nota publicada en el número 42 (octubre de 1983) del suplemento Libros. Gaceta de información bibliográfica, E1 Áncora fue presentada como "la mejor editorial colombiana [debido] a sus títulos, las sobrias ediciones, las carátulas" (Libros. Gaceta de información bibliográfica, 1983, s.p.), una calificación que permite dar cuenta del reconocimiento con el que la empresa contaba en el mercado nacional, en el que para la fecha compartía espacio con otras editoriales como Tercer Mundo, Carlos Valencia y Oveja Negra, ${ }^{2}$ las dos primeras con catálogos similares al de Hoher y Escobar, con tendencia a los temas de ciencias sociales.

2 Sobre estas tres editoriales, veánse los trabajos de Danilo Penagos, Paula Marín Colorado y María Camila Cardona incluidos en el presente dossier. 
Esta difusión es un indicio del lugar que ocupaba El Áncora en el mercado en esa época, es decir, en el centro del liderazgo editorial colombiano durante el periodo de finales del siglo xx y principios del xxı.

Fuente: fotografía tomada por Paula Marín Colorado al ejemplar de la Biblioteca Luis Ángel Arango de Bogotá.

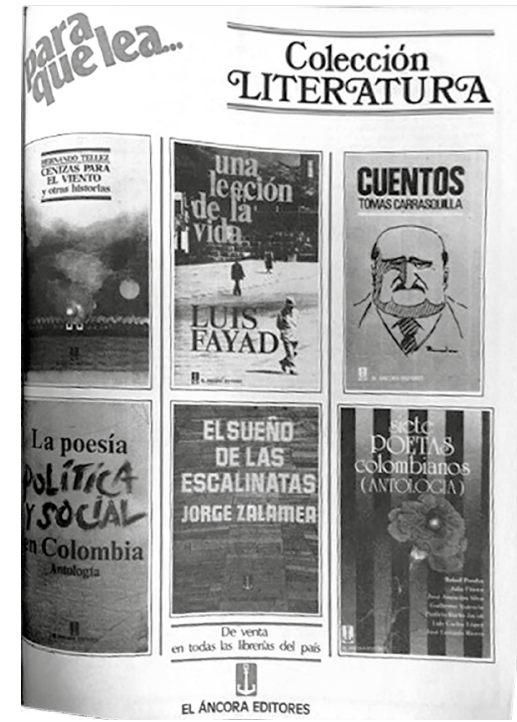

Figura 2. Publicidad en Magazine Dominical de El Espectador, mayo de 1985.

Fuente: fotografía tomada por Paula Marín Colorado al ejemplar de la Biblioteca Luis Ángel Arango de Bogotá.

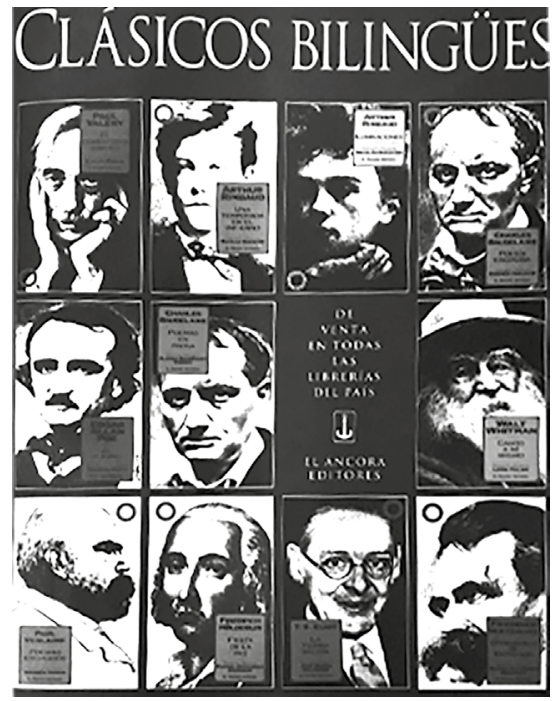

Figura 3. Publicidad en Magazine Dominical de El Espectador, abril de 1995. 
Como lo confiesa Escobar (2018), el declive de E1 Áncora comenzó en el año 2017 con la muerte de Hoher, debido a que

\begin{abstract}
[...] esta fue una empresa producto de la relación emocional que tuvimos Patricia y yo, y en ausencia de Patricia, pues digamos que las reglas del juego cambian por completo, y además yo me doy cuenta después de la muerte de Patricia de que administrar [...] y manejar las ventas de una editorial como esta es un camello, como se dice coloquialmente, que yo no me imaginé que fuera tan grande porque yo, si tú quieres de una manera un poco egoísta, yo me entendía de la producción de los libros y Patricia de la parte comercial. Y ahora me doy cuenta de que eso es un trabajo muy exigente y no estoy muy seguro de que en ausencia de Patricia yo pueda estar al frente de eso. Esa es la situación.
\end{abstract}

La producción de El Áncora ha variado con los años (figura 4), aunque últimamente ha tendido a la baja. Comenzó con éxito gracias a la publicación de libros de temas sociales, literatura nacional y trabajos investigativos; pero en la década de los 90 , el auge de las editoriales universitarias y la puesta en marcha de una política de apertura económica que afectó el sector nacional causaron una baja en las ventas que significó una crisis de la industria editorial colombiana, "hasta el punto de que varias editoriales [La Oveja Negra, Tercer Mundo, Carlos Valencia, El Áncora], que eran muy creativas en ese entonces, tuvieron un bajonazo muy grande en cuanto a las ventas se refiere" (Escobar, 2018). Por ello, a pesar de que los editores de El Áncora pudieron evitar el quiebre de la empresa, su labor se vio afectada. Aunque hoy en día todavía sigue funcionando, la posición que ostentaba hace casi 40 años en el mercado nacional no es la misma: con un promedio de 3 libros por año en lo que va del siglo xxi, está muy lejos de los 12 que promediaba en su primera década de vida.

Para Felipe Escobar (2018), El Áncora es una editorial “independiente” porque es "una editorial privada que vive de vender libros", y además se caracteriza por el hecho de que los editores deciden qué libros y autores se publican, sin la presión de incluir en su catálogo textos cuya venta está asegurada en el mercado; es decir, su empresa no hace parte de una red de grandes conglomerados de la comunicación y tampoco pertenece a editoriales afines al Estado colombiano. Esta autoafirmación se sustenta con la propuesta de que la identificación (propia o ajena) de una editorial como "independiente" conlleva una serie de representaciones, prácticas y tomas de 
posición que las ubican de determinadas maneras dentro del campo editorial. Para Saferstein y Szpilbarg (2012), los editores se pueden considerar independientes en el sentido de que no dependen de los parámetros que el mercado impone en términos económicos (p. 472); aunque la validación o rechazo de esta clasificación no constituye el objeto de este texto, es importante tenerlo en cuenta para el posterior análisis del catálogo de libros publicados por la editorial y también para comprender la situación actual de El Áncora.

Fuente: Elaboración propia.

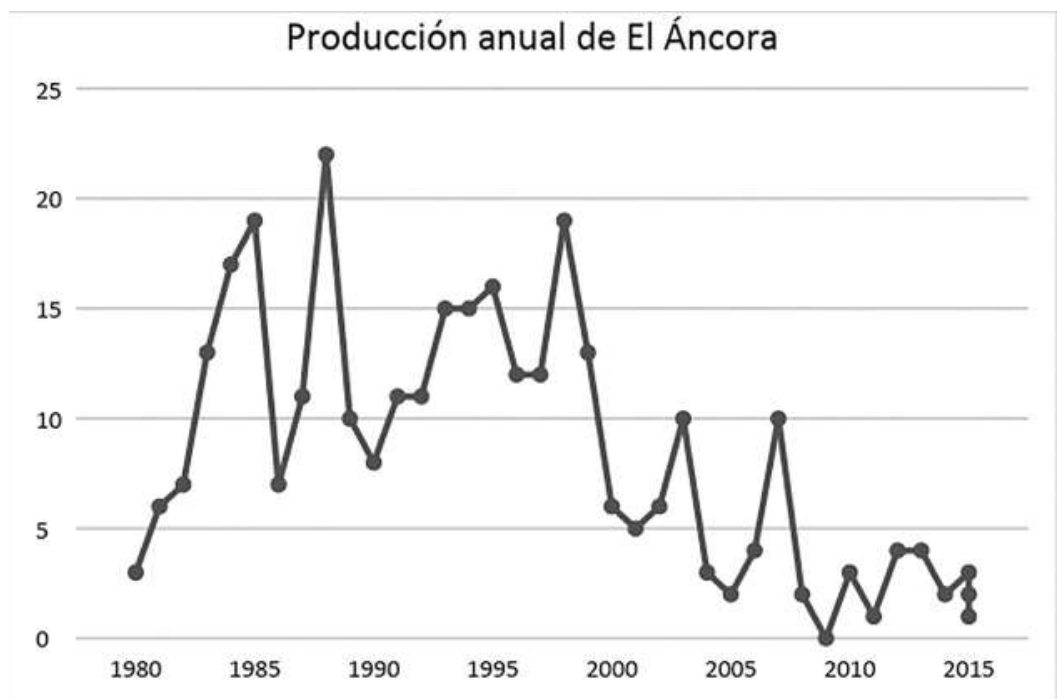

Figura 4. Producción de El Áncora Editores por año.

\section{El catálogo de El Áncora}

Los años 70 y 80 del siglo xx estuvieron marcados por movimientos sociales concentrados en los conflictos armados que ensombrecieron a la nación colombiana durante décadas, reflejo de aquellos que desde años antes estaban azotando distintas regiones de Latinoamérica. En este sentido, El Áncora surgió en un momento de la historia de Colombia en el cual los jóvenes universitarios y la clase media (los principales lectores y compradores de libros) se interesaban por un movimiento revolucionario contrario al control del Estado y de grupos violentos (Monsalve y 
Valencia, 2014), esto según lo expresó Felipe Escobar en entrevista con la Radio Nacional de Colombia en 2014. Con ese pensamiento en mente, en 1980 publicaron los tres títulos que inauguraron el sello: Cuentos de Tomás Carrasquilla, ${ }^{3}$ Memorias de la guerra de los Mil Días de Lucas Caballero y una selección titulada Escritos Políticos de Simón Bolívar. Para sorpresa de los editores, fueron un éxito comercial, pues contaron con varias reimpresiones y reediciones en esta misma editorial, y les otorgó el entusiasmo y la base económica necesaria para continuar con su labor.

Dichos libros marcarían la línea editorial que siguieron sus fundadores a partir de entonces, tal como se ha evidenciado en el trabajo de reconstrucción del catálogo general de esta editorial y conforme a lo que Felipe Escobar manifestó en la conversación sostenida en julio de 2018. De acuerdo con Simonin (2004), quien se basó en una propuesta anterior de François Maspero, el catálogo es un libro de libros que presenta un retrato del editor en la medida en que revela su actividad editorial, y en su definición más simple es el conjunto de todos los libros publicados por una editorial desde su fundación (p. 119). Como ya se ha dicho, la presente investigación se basa en la reconstrucción del catálogo de libros publicados, para lo cual se realizó la revisión virtual en los archivos de algunas bibliotecas nacionales, ${ }^{4} \mathrm{y}$ la posterior revisión física de los mismos, con el fin de observar de primera mano las características materiales, teniendo en cuenta a Chartier (1993) cuando dice que "la disposición de la página impresa, las modalidades de la relación entre el texto y lo que no lo es [y] también la ordenación misma del libro" son significativos "en el proceso de producción literaria" (p. 20). Gracias a este proceso de revisión de las fuentes se pudo obtener la información necesaria para completar las matrices de datos que permitieron reconstruir el catálogo de libros impresos de El Áncora. ${ }^{5}$ Además, se contó con un listado de libros de la editorial, suministrado por Felipe Escobar, quien confesó estaba incompleto, pues desde hace varios años no era actualizado; ${ }^{6}$

3 El Áncora tuvo los derechos exclusivos de las obras de Tomás Carrasquilla. Aunque no es objeto de este trabajo, es pertinente señalarlo debido al "capital simbólico" que este autor representa en la literatura nacional. En Bogotá: Biblioteca Luis Ángel Arango y Biblioteca Nacional. En Medellín: Biblioteca de la Universidad de Antioquia, Biblioteca de la Universidad Eafit, Bibliotecas EPM, Biblioteca Pública Piloto.

5 Matrices elaboradas a partir del trabajo de Doré (2017), y que recolectan datos como número de páginas, reediciones, ilustraciones, traducciones, tipo de papel, presencia de paratextos, tiraje, entre otros.

6 Es necesario decir que El Áncora no cuenta con página web ni ubicación física de la empresa. Las actividades eran realizadas personalmente por sus fundadores desde su residencia privada. 
sin embargo, gracias a él se pudo observar la existencia de títulos que no aparecen en las bibliotecas del país y que por ello no pudieron ser revisados físicamente, a pesar de que se contaron en las estadísticas generales presentadas más adelante. ${ }^{7}$

La reconstrucción realizada hasta la fecha de escritura de este texto arroja un total de 320 libros publicados entre 1980 y 2016, ${ }^{8}$ de los cuales el 70 \% están relacionados con temas de historia, política, sociología, antropología, periodismo, humor y otros, mientras que el $30 \%$ restante corresponde a obras literarias: poesía, novela, cuento, teatro y cuadro de costumbres (tabla 1). ${ }^{9}$ Así se puede ver que el interés principal de El Áncora está centrado en temas de las ciencias sociales y humanas, aunque esto no significa que se excluyan otras áreas. Lo anterior da como resultado un catálogo diverso. Del mismo modo, el tema colombiano (bien sea obra de autores nacionales o no) concentra el mayor volumen de las obras, con un total de 244, casi el 78 \% del catálogo. Ello es coherente con las palabras de Felipe Escobar (2018) cuando dijo que su interés era "publicar libros críticos, libros que den una visión distinta a la que dan los medios masivos de comunicación del país sobre los temas de la sociedad colombiana", con el significado de los títulos que inauguraron la editorial y, también, con su relación con catálogos como el de Carlos Valencia Editores, comprado por El Áncora, y que comprendía

[...] básicamente dos tipos de libros: libros de ciencias sociales, que nos interesaban muchísimo, sobre todo a mí, y tenía una colección muy completa y muy bonita de libros infantiles [...]. Cuando compramos Carlos Valencia y comenzamos a ver qué íbamos a reeditar de los libros agotados, nos dimos cuenta de que hacer libros infantiles es todo un arte, distinto al de hacer otro tipo de libros; y nos dimos cuenta de que nosotros no sabíamos hacer libros infantiles. Entonces Patricia le vendió todo el catálogo de la editorial Carlos Valencia a Panamericana (Escobar, 2018).

7 Estos libros son: Apuntes de viaje de Magdalena Fety de Holguín, Ensayos sobre economía laboral colombiana de Hugo López, El Estado como mercado de Edgar Revéiz, Notas de la expedición Fidalgo de Joaquín Francisco Fidalgo, y Relaciones civico militares en Colombia (sin dato de autor).

Felipe Escobar suministra una cifra aproximada de 500 libros publicados, dentro de los cuales incluye las reediciones y reimpresiones. Pero debido a que no se cuenta con un catálogo de la editorial, no es posible conocer la cantidad exacta, pues depende de la reconstrucción con los títulos en las bibliotecas faltantes, la cual sigue en curso.

9 Esta clasificación se ha hecho teniendo en cuenta aquella que aparece en los libros, bien sea en el título, en la colección o en los paratextos. $\mathrm{O}$, en su defecto, en los mismos catálogos de las bibliotecas, luego de compararse con el contenido de los libros y asegurar que la clasificación no es errada (lo cual hasta el momento no ha ocurrido). 
Tabla 1. Catálogo de El Áncora Editores por temas.

Fuente: Elaboración propia

\begin{tabular}{|c|c|c|c|}
\hline Materia & Porcentaje & Tema & Cantidad de títulos \\
\hline \multirow{13}{*}{ Ciencias sociales } & \multirow{13}{*}{$70 \%$} & Historia & 102 \\
\hline & & Periodismo & 41 \\
\hline & & Biografía & 22 \\
\hline & & Política & 18 \\
\hline & & Humor & 8 \\
\hline & & Arquitectura & 7 \\
\hline & & Arte & 6 \\
\hline & & Filosofía & 5 \\
\hline & & Antropología & 4 \\
\hline & & Economía & 2 \\
\hline & & Sociología & 1 \\
\hline & & Psicología & 1 \\
\hline & & Ensayos & 5 \\
\hline \multirow{5}{*}{ Literatura } & \multirow{5}{*}{$30 \%$} & Poesía & 56 \\
\hline & & Novela & 20 \\
\hline & & Cuento & 18 \\
\hline & & Teatro & 3 \\
\hline & & Cuadros de costumbres & 1 \\
\hline
\end{tabular}

Dada la amplitud del catálogo reconstruido, en esta oportunidad se hará mención solo de algunos títulos publicados por El Áncora que pueden dar una idea de la variedad de obras y autores que aparecieron bajo el sello editorial.

Ya se ha mencionado la proporción entre libros de ciencias sociales y los de literatura, sin embargo es importante resaltar que dentro de este último grupo fueron publicados textos y autores que cuentan con reconocimiento nacional e internacional. Tal es el caso de las tragedias de William Shakespeare: Macbeth y El Rey Lear, ambas publicadas en el año 1988 en formato de 19x12 cm, encuadernación rústica y con 
prólogo y traducción de Jorge Plata. Siguiendo con obras extranjeras ya conocidas por la mayoría del público lector, se encuentran Los desterrados y otros cuentos de la selva (1993) de Horacio Quiroga, y la serie de poesía bilingüe (1993-2000) que contó con nombres como Paul Valéry, Arthur Rimbaud, Charles Baudelaire y Oscar Wilde. Estos últimos eran libros que oscilaban entre las 70 y 120 páginas, y que además fueron ampliamente publicitados en el Magazine Dominical de El Espectador, tal como se puede evidenciar en la figura 4.

Al lado de estos escasos títulos de literatura extranjera (27 del total), aparecieron los libros de autores colombianos con trayectoria, como Tomás Carrasquilla (Frutos de mi tierra y La Marquesa de Yolombó, en 1987), Porfirio Barba Jacob (Poesía completa, 1988) y Jorge Isaacs (María, 1989); siendo el libro de Cuentos de Carrasquilla uno de los que inauguró la editorial en el año 1980, como ya se había comentado.

Además, en El Áncora la figura de la colección es importante ya que, como lo afirman Rivalan y Nicoli (2017), contribuyen a la construcción o consolidación de las identidades nacionales (p. 21), ello al estar formadas bajo decisiones que toman sus editores dentro de un contexto externo que "les determina y se les escapan" (Doré, 2012, p. 290); decisiones que están influenciadas por aspectos como la necesidad del público lector en cuanto a temas de lecturas, el cual está íntimamente ligado al mercado y a la posibilidad de beneficios económicos, la situación política o social del entorno en el cual está inmerso el producto que se quiere presentar, entre otros no menos importantes. En este sentido, entre las colecciones de El Áncora se cuentan "Literatura Colombiana", 10 "Periodismo de Hoy"y "Escritos Políticos"; ${ }^{11}$ y otras series que, aunque no tienen el rótulo de "colección", pueden ser clasificadas como tales debido a la homogeneidad de su presentación física y de la temática que los unifica como un todo, como por ejemplo las biografías ilustradas, historia de la costa, ${ }^{12}$ poesía bilingüe, entre otras, reconocidas por Felipe Escobar (2018) como colecciones.

10 Década de 1980, en coedición con Arango Editores. Entre las obras que la conforman, está la novela María de Jorge Isaacs, Cenizas para el viento y otras historias de Hernando Téllez, la Poesía completa de Porfirio Barba Jacob, y otros.

11 Selección de textos escritos por grandes figuras de la historia nacional, en menos de 200 páginas y libros de pequeño formato (18 $\mathrm{cm}$ alto por $10 \mathrm{~cm}$ de largo). $\mathrm{E} 1$ primer título (Simón Bolívar) inauguró el catálogo de El Áncora en 1980, y la última entrega de esta colección hallada hasta ahora (Francisco de Paula Santander) se publicó en el año 2003.

12 Historia doble de la costa de Orlando Fals Borda. En 4 tomos, fruto de casi dos décadas de trabajo investigativo y político del autor, presentado en tomos de gran formato, papel esmaltado y tapa dura. 
Otra colección que vale la pena destacar es la antología de la Selección Samper Ortega de Literatura Colombiana en el año 2007, diez tomos de los cien originales que antes habían sido publicados por la editorial Minerva entre los años 1928 y 1936. ${ }^{13}$ Daniel Samper Ortega (1895-1943) fue un escritor, editor de revistas y director de la Biblioteca Nacional de Colombia que en 1928 decidió realizar una revisión bibliográfica de la literatura nacional a través de la compilación de una serie de textos de autores colombianos desde principios del siglo xIX hasta su presente, con la cual buscaba fortalecer la literatura nacional por medio del rescate de obras que consideraba fundamentales para el público lector colombiano del siglo xx (Pineda Cupa, 2017, p. 01). Esta nueva edición fue seleccionada por Juan Gustavo Cobo Borda y contó con el patrocinio de Seguros Bolívar, una compañía colombiana de capital privado dedicada a los servicios financieros. Las diez secciones originales en las cuales clasificó Samper su colección fueron conservadas en la nueva edición de El Áncora, pero la selección de Cobo Borda redujo en gran medida los más de 2500 textos iniciales.

La editorial es constante en su propuesta de acercar a los lectores al conocimiento sobre la cultura colombiana, con libros como Las fiestas y el folclor en Colombia (1985), Mitos colombianos (1988) y Supersticiones y agüeros colombianos (1989), todos de Javier Ocampo López; y en el plano literario, con los títulos Quién es quién en la poesía colombiana (1995) y la Antología de la poesía colombiana (1998), ambos del poeta y periodista cultural Rogelio Echavarría, que permiten conocer el desarrollo de este género en Colombia a través de distintos momentos históricos, en un esfuerzo por resaltar la escritura poética nacional.

El interés por la historia de Colombia retoma la historia contemporánea y se remonta hasta los relatos de la Conquista y la Colonia por parte de los exploradores europeos. Es así como aparece dentro del catálogo de El Áncora la publicación de los documentos de Mutis y la expedición botánica (1983) seleccionados por Gabriel Fonnegra; ${ }^{14}$ del mismo modo un libro llamativo por su diseño de alto costo que se publicó en el cuarto año de vida de la editorial, titulado América pintoresca. Descripción de viajes al Nuevo Continente por los más modernos exploradores (1984), la reedición

13 Al respecto, veánse los trabajos de Juan David Gil.

14 En pequeño formato, pero con ilustraciones presentadas en papel esmaltado. 
de una obra publicada por primera vez en el año 1884, y que contiene una serie de grabados en los cuales los exploradores europeos reflejaron todo su asombro por las maravillas descubiertas en el Nuevo Mundo. Como ocurre con casi todos los títulos que contienen fotografías y grabados, el formato de este libro es de gran tamaño, cubierta dura y papel esmaltado, lo que garantizaba la calidad de las ilustraciones.

Para facilitar un poco exposición de la trayectoria de esta editorial, se propone una periodización del catálogo teniendo en cuenta las décadas de funcionamiento de E1 Áncora (figura 3). De este modo, se delimitan tres etapas de vida de la empresa en las cuales se pueden observar distintas dinámicas de publicación: primeros diez años (1980-1990), segunda década (1991-2000) y nuevo milenio (2001 hasta la actualidad); esta división sugiere formas de funcionamiento diferentes a partir de la identificación de tendencias en el catálogo que pudieron responder a decisiones editoriales para asegurar el funcionamiento de la empresa en cada periodo, tal como se intentará demostrar a continuación con datos cuantitativos de cantidad de libros publicados, cuántos eran de literatura, número de reimpresiones, reediciones y coediciones.

\section{Fuente: Elaboración propia}

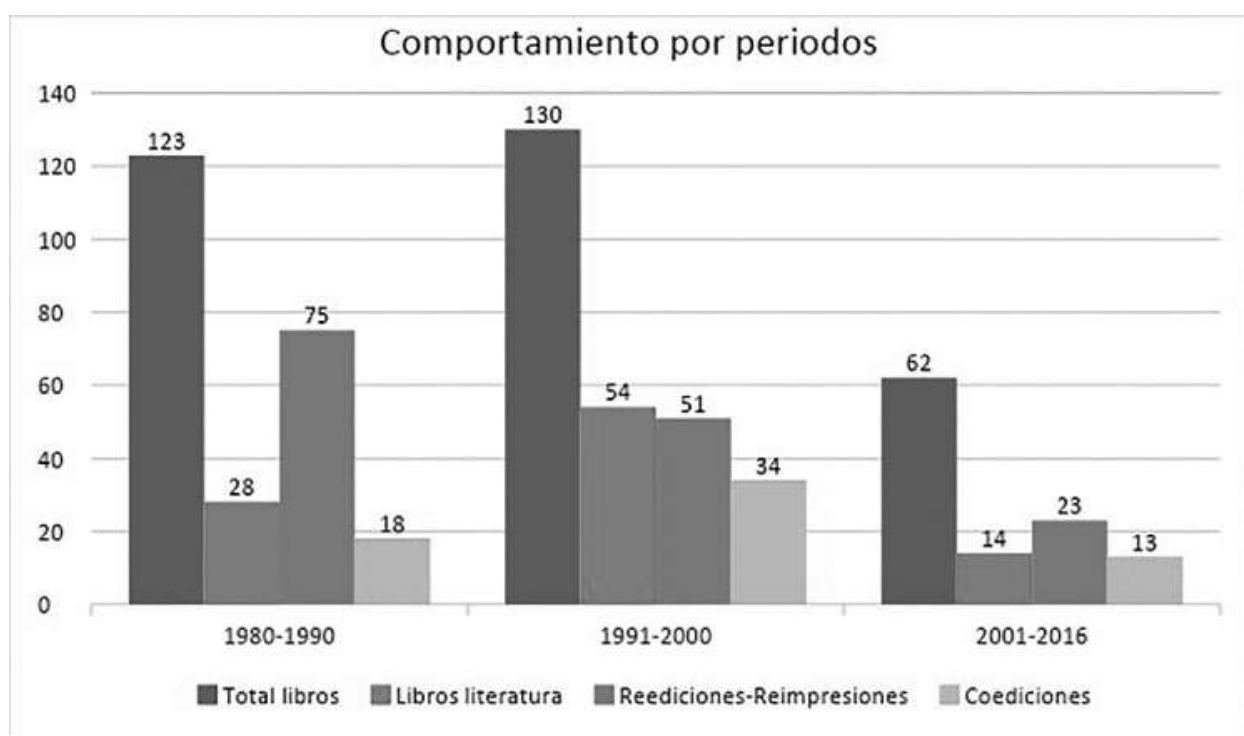

Figura 5. Publicación de títulos de El Áncora por periodos. 
Durante los primeros diez años, que van desde su fundación en 1980 hasta el año 1990, la editorial publicó un total de 123 libros, 28 de los cuales fueron de literatura y el resto de ciencias sociales y humanas. Durante este periodo tuvieron mucho éxito la colección de biografías ilustradas de Javier Covo Torres (finales de 1980) y los libros compilatorios de las columnas periodísticas de Lucas Caballero, ${ }^{15}$ cuyo título Klim. 45 años de humor (1983) ha sido el de mayor tiraje en la editorial (25000 ejemplares), según lo hallado hasta el momento en la investigación. Además, tanto los de Covo Torres como los de Caballero aparecieron entre los libros más vendidos de Colombia en ese momento, de acuerdo con las listas publicadas en la época por el suplemento Lecturas Dominicales del periódico El Tiempo de Bogotá. ${ }^{16}$

Durante la segunda década, que comprende el año 1991 hasta el 2000, se registró un incremento en el total de libros publicados, una disminución de reimpresiones y reediciones, así como un aumento de obras que son producto de traducciones y otras realizadas en coediciones. De los 130 títulos publicados en este periodo, 54 son de literatura.

La estrategia de la coedición (34\% de los libros fueron publicados bajo esta modalidad) es indicio de una caída de la producción editorial, pues se debió acudir a estas estrategias para asegurar un capital de funcionamiento. La relación con el Estado se hace evidente en este periodo con la presencia de muchos títulos coeditados con el Banco de la República y el Ministerio de Cultura, ${ }^{17}$ así como con otras empresas privadas. Las traducciones también presentaron un aumento, al pasar de un $17 \%$ en la década anterior a un $31 \%$ en este periodo, tratándose principalmente de obras por las que no debían pagar derechos de autor y con una presentación sencilla que no representara un alto costo de producción (Escobar, 2018). Dentro de las traducciones se ubica la colección de poesía bilingüe, que, si bien contó con críticas positivas y amplia publicidad en medios impresos, no dejaba de ser un producto distinto al acostumbrado por la editorial, en el sentido de que no eran obras inéditas de autores

15 En el catálogo de El Áncora se encuentran libros de varios miembros de la familia Caballero a lo largo de los años.

16 Ver, por ejemplo, suplementos publicados en enero de 1984, diciembre de 1987, febrero y junio de 1988.

17 Queda pendiente profundizar en esta relación. 
o temáticas colombianas. Adicional a ello, la edición por encargo fue otra estrategia para mantener un buen nivel de ventas. ${ }^{18}$

El tercer periodo de El Áncora, que va desde el año 2001 hasta el 2016 (año del último libro hallado en los archivos), ${ }^{19}$ se puede extender hasta la actualidad si se tiene en cuenta que la editorial sigue en funcionamiento, aunque ahora se dedica principalmente a la publicación de libros por encargo y a la venta de derechos de sus títulos publicados. Como es de suponer según lo presentado hasta el momento, este es el periodo menos productivo de la empresa, pues solo alcanza un total de 62 títulos publicados en 16 años; una disminución abrupta si se compara proporcionalmente con el comportamiento de periodos anteriores. De ese total, 14 son obras de literatura.

\section{A modo de conclusión}

De acuerdo con Saferstein (2017, p. 145), los libros son un espacio de circulación de ideas, un producto que es el resultado de la selección previa que hacen los editores, y por medio de los cuales estos últimos intervienen en la esfera pública. Las obras que forman parte de un catálogo editorial, por un lado, muestran la posición ideológica de quienes están al frente de esa empresa, y, por otro, son producto y consecuencia de la época en la que se inscriben. Ejemplo de ello es El Áncora Editores, cuyo catálogo reconstruido hasta la fecha y sus entrevistas demuestran la apuesta de sus editores en función a su ideología personal, la cual querían transmitir a través de las obras presentadas al público, centradas en temas nacionales, trabajos periodísticos y de historia nacional.

Este artículo forma parte de un trabajo de mayor alcance, en el que se propone comprender la dinámica, trayectoria y mostrar el legado de esta empresa, sumándose al objetivo principal de los estudios recientes alrededor de la cultura impresa en Colombia, de gran relevancia para comprender las dinámicas de producción y circulación de la literatura nacional. Al poseer un amplio repertorio de obras literarias nacionales, también se está considerando desarrollar un estudio específico en esta línea, ampliando de esa forma la investigación en curso. 


\section{Referencias bibliográficas}

Chartier, R. (1993). Libros, lecturas y lectores en la Edad Moderna. Madrid: Alianza Editorial.

Doré, M. (2017). La New Canadian Library, 1957-2011: modelo de análisis de una colección literaria. En M. Nicoli y C. Rivalan. La colección. Auge y consolidación de un objeto editorial (Europa/Américas, siglos XVIII-XXI (pp. 269-290). Bogotá: Universidad de los AndesUniversidad Nacional de Colombia.

E1 Áncora. (octubre de 1983). Libros. Gaceta de información bibliográfica 42, s.p.

Escobar, F. (2018). Conversación con Almary C. Gutiérrez Díaz. Bogotá, 25 de julio.

Marín Colorado, P. A. (2018). Edición en Colombia (1970-1990): del boom de la industria gráfica a la diversificación de la industria editorial. En D. Guzmán et al (Eds.). Lectores, editores y cultura impresa en Colombia. Siglos XVI-XXI (pp. 384-410). Bogotá: cERLALC-Universidad Jorge Tadeo Lozano.

Monsalve, J.A. y Valencia, M. (31 de agosto de 2014). Los libros. Entrevista con Felipe Escobar - Parte 1. Radio Nacional de Colombia. Recuperado de: https://www.radionacional.co/episodio/los-librosfelipe-escobar-parte-1 15.08.2019].

Pineda Cupa, M. A. (2017). Semblanza de Selección Samper Ortega de Literatura Colombiana (19281937). En Biblioteca Virtual Miguel de Cervantes - Portal Editores y Editoriales Iberoamericanos (siglos $X I X-X X I)$ - EDI-RED. Recuperado de: http://www.cervantesvirtual.com/obra/seleccionsamperortega-de-literatura-colombiana-1928-1937-semblanza-788529/ [15.08.2019].

Publicidad (30 de junio de 1985). Magazine Dominical de El Espectador 118, s.p.

Ribadero, M. (2016). Tiempo de profetas. Bernal: Universidad Nacional de Quilmes.

Nicoli, M. y Rivalan, C. (2017). La colección. Auge y consolidación de un objeto editorial (Europa/Américas, siglos XVIII-XXI). Bogotá: Universidad de los Andes-Universidad Nacional de Colombia.

Saferstein, E. (2017). La edición como intervención cultural, comercial, y política: best-sellers políticos del director de Random House-Sudamericana en el kirchnerismo. Millcayac - Revista Digital de Ciencias Sociales 4 (7), pp. 141-164. Recuperado de: http://revistas.uncu.edu.ar/ojs/index.php/ millca-digital/article/view/1022/626 [15.08.2019].

Saferstein E. y Szpilbarg, D. (31 de octubre de 2012). El espacio editorial "independiente": heterogeneidad, posicionamientos y debates. Hacia una tipología de las editoriales en el período 1998-2010. Ponencia presentada en el Primer Coloquio Argentino de Estudios sobre el Libro y la Edición, La Plata, Argentina. Recuperado de: http://www.memoria.fahce.unlp.edu.ar/trab eventos/ev.1955/ev.1955.pdf [15.08.2019].

Simonin, A. (2004). Le catalogue de l'éditeur, un outil pour l'histoire. L'exemple des éditions de Minuit. Vingtième Siècle. Revue d'histoire 81, pp. 119-129. DOI: http://doi.org/10.3917/ving.081.0119 